REVIEW ARTICLE

\title{
Personality disorders in DSM classifications
}

\section{Lidia Cierpiatkowska}

Department of Health Psychology and Clinical Psychology, Institute of Psychology, Adam Mickiewicz University, Poznan, Poland

In the article an overview of history of personality disorders' diagnostic criteria has been presented since the publication of The Diagnostic and Statistical Manual of Mental Disorders (DSM) in 1952 up to the fifth edition published in 2013. Describing the beginnings of the classification in psychology, theses of a German philosopher and psychologist William Stern (1871-1938), the founder of psychology of individual differences have been examined, as he defined 'type' as a dominating psychological or psychophysiological predisposition. Changes in typologies in subsequent editions of DSM were aimed at increased accuracy of description of differentiated personality disorders' types. The goal of such descriptions was to increase the accuracy of clinical diagnosis of individuals displaying in various domains of life repeated perceptional and behavioral patterns. Since the first edition of DSM the categorical perspective has been emphasized, which in the present edition has been replaced by the dimensional - categorical model, defined as a hybrid one. This change has already led to various controversies and discussions, and therefore requires further research.

KEY WORDS

personality disorders; typology; manual; diagnosis

CORRESPONDING AUthor - Lidia Cierpiałkowska, Department of Health Psychology and Clinical Psychology, Institute of Psychology, Adam Mickiewicz University in Poznan, 89 Szamarzewskiego Str., 60-568 Poznan, Poland, e-mail: Icierp@amu.edu.pl

AUthors' CONTRIBUtion - A: Study design - B: Data collection - C: Statistical analysis - D: Data interpretation . E: Manuscript preparation · F: Literature search · G: Funds collection

to CITE thIS ARTICLE - Cierpiałkowska, L. (2013). Personality disorders in DSM - psychopathology and classifications. Current Issues in Personality Psychology, 1, 1-10. 


\section{BACKGROUND}

Mature personality and various forms of its disorders have been the subject of interest for researchers and clinicians who continue creating new concepts for their differentiation. Medical models and classifications have developed criteria to differentiate personality disorders from other clinical units and have indicated characteristic features of those types of personality disorders. There are two main search trends in psychology attempting to determine how to conceptualise and form a description of personality (cf. Widiger \& Costa, 1994; Lenzenweger \& Clarkin, 1996; Clarkin, 2006). The first approach, often called paradigmatic, is based on the assumption of the human essence lying in our psyche, and resulting premises concerning the developmental paths of normal and impaired personality subject to empirical verification (e.g. concepts of Kernberg, 1980; Beck, Freeman \& Devis, 2005). The second one stems from the theory of attributes which not only studies the stability of attributes and behavioural dispositions but also searches for individual differences between people, indicating characteristic profiles of intensified personality traits in normal people and those with mental disorders (e.g. models by Costy \& McCrea, 1995; Clonninger, 1997).

One of the most difficult questions in psychiatry and psychology, still lacking a sufficiently accurate answer, is how to differentiate the functioning style of an individual (strictly related to personality traits) from the behaviour patterns of people with personality disorders. In other words, it is a question about the criteria of differentiating between normal and impaired personality that prevents adaptive behaviours not so much in standard situations as in difficult ones that present a challenge, loss or threat.

The purpose of this paper is to present the contribution of psychiatric tradition and psychology of individual differences to the formation of various classifications of personality disorders. With the publication of the fifth American issue of the Diagnostic and Statistical Manual of Mental Disorders (DSM, APA, 2013) a day before the issue of the eleventh version of the International Classification of Diseases and Related Health Problems (ICD) it is worth looking into the modifications, which, for personality disorders, seem radical. These changes raise numerous doubts and protests, although introduced with the intention to improve the accuracy of differential (nosological) diagnosis (cf. Livesley, 2012).

\section{PERSONALITY DISORDERS IN THE HISTORY OF PSYCHIATRY AND PSYCHOLOGY OF INDIVIDUAL DIFFERENCES}

For the first time the notion of type with regard to the dominant mental or psychophysical disposition was defined by the German philosopher and psychologist William Stern (1871-1938), the author of the monograph "Über Psychologie der individuällen Differenzen: Ideen zu einer differenziellen Psychologie" ("On psychology of individual differences: Ideas of differential psychology", 1900), commonly considered the creator of the psychology of individual differences (Strelau, 1985, 2000). Stern said that certain sets (collections) of dispositions might be a basis for the differentiation of various classes of people who do not completely differ from others but at the same time are similar to them with regard to other traits.

Apart from the difference criterion in mental or psychophysical dispositions in the type differentiation, C.G. Jung (1960) raised the issue of repeatability and stability. Creating one of the first personality typologies in psychology, Jung defined a type as a repeating, characteristic pattern of what is potentially typical for the entire human population. Allport considered relative stability of personality traits as a premise for the prediction of human behaviours (Pervin, 2000, p. 52). Since then personality psychologists have been investigating to what extent behaviours observed in specific situations allow us to predict behaviour in other situations and contexts and how these behaviours remain unchangeable across time.

Analysing the meaning and contexts in which the category of type was used in the psychology of individual differences Strelau (2000) indicated its certain characteristic. The notion of type is a classification category since it is intended for the creation of classes (groups) of people characterised by certain traits or characteristics. A person does not have a type, but belongs to a type since he or she shows a certain pattern of experiencing or behaviour which is a criterion to distinguish a type (ibid., p. 655). In contrast to a type, a trait is relatively constant (consistent in time), and characteristic for a particular person, a tendency for certain behaviours that appear in similar situations and social contexts (situational coherence) (Mischel, 1990). In psychometrics the notion of trait is used interchangeably with ability, which not only is manifested as a pattern of behaviour, but also specifies relatively constant psychical, physiological or anatomical characteristics. Borderlines between these types are relative as each individual belongs to a specific type only due to certain characteristics, e.g. cognitive skills, but may also belong to a different type than people with similar cognitive skills, e.g. due to his or her characteristic manifested in interpersonal relations. In consequence, it needs to be assumed that a type marks and includes both what is general and individual. A trait or ability is not only a characteristic differentiating one person from another, but also a personality construct intended to explain the time stability and situational coherence of behaviour (Mischel, 1990). 
The ever-present and common passion for classifying physical phenomena was quickly expressed in attempts to distinguish groups of people differing from one another in the population. Studying the history of psychological thought we can track the history of various typologies originating from psychological concepts, clinical observations or empirical inquiries. The largest differences are observed between the clinical and statistical (quantitative) approaches since they use different research methods, procedures and methods of result preparation (Pervin, 2000; Oleś \& Drat-Ruszczak, 2010). The clinical approach proposes and is based on psychological models or concepts of men, whereas the statistical approach emphasises the individual differences with regard to personality traits and indicates their mutual relations.

The earliest attempts at classification of people were temperament typologies based on the assumption of relationships between the proportion of fluids (humours) in the human body and its physical and mental condition. Referring to four elements distinguished by Empedocles, first Hippocrates in the $4^{\text {th }}$ century $\mathrm{BC}$ and several years later Galen indicated blood, phlegm, yellow bile and black bile that determined the temperament. Galen used the assumptions of Hippocrates and isolated nine types of temperament. Four of them depended on the domination by one of the fluids: domination of blood (Latin sanguis) constituted a sanguine; yellow bile (Greek cole) choleric; black bile (Greek malas) and yellow bile melancholic; and mucus and phlegm (Greek phlegma) - phlegmatic. Although the first proposition, called the Hippocrates-Galen typology, was based on psychophysiology, its relationships with environmental characteristics were also emphasised. Climate and temperature were considered significant for the formation of basic personality traits, e.g. aggressiveness or mildness. It was concluded that a moderate climate was related to mildness, whereas extreme climates aroused strong emotions and passions. While the temperament typology created by Hippocrates-Galen was the first classification referring to experience and observation results, the truly experimental approach to personality was outlined in the works of Francis Galton (1822-1911) and Ivan P. Pavlov (1849-1936) (Pervin, 2000).

The roots of the clinical approach to personality disorders should be sought for in two various trends: those related to psychiatric classifications and those stemming from psychoanalytical (psychodynamic) thinking. In the psychiatric tradition the beginnings of European conceptualisation of personality disorders were usually related to the work of Phillippe Pinela (1801, after: McCord \& McCord, 1964); whereas the English-American one was associated with the psychiatrist Benjamin Rush (1812, after: Arrigo \& Shipley, 2001). Although it was Rush who described a nosological entity called moral derangement, refer- ring to people characterised by a tendency to socially destructive and deviant behaviours in various areas of life (e.g. lies, deception, unrestrained impulse), the knowledge on this subject was popularised by James Prichard (1835, after: Sa $\beta$ \& Felthous, 2007). After numerous changes to the name of this clinical entity, Prichard developed the notion of morally defective, indicating two types: one applying to intellectual underdevelopment and the other to feelings and will. Moral derangement applies to the second of these disorders where a significant role is played by the disposition for perverse, compulsive experiencing of feelings which temporarily may also occur in other people. Such persons are morally depraved, unable to observe standards and social rules and lack any remorse. In this disorder there are no intellectual defects or any psychotic symptoms. Undoubtedly, Prichard enriched earlier clinical descriptions of the discussed illness which is currently called the antisocial personality disorder.

At the same time, the psychoanalytical trend developed, including first typologies of personality disorders created by students of Jean Charcot, a psychiatrist who ran a world-renowned clinic in Paris. Pierre Janet (1825-1893) was the first of Charcot's famous students to publish results of very interesting clinical observations on hysterical personality, indicating significant differences between its overt and covert traits. On the other hand, Morton Prince (1854-1929) described a multiple personality, seeking its origin in the unconscious mechanism of dissociation (split). Finally, Sigmund Freud (1856-1939), the author of neurotic personality theory and a commonly known therapeutic method, launched a relatively coherent set of assumptions comprising a structural, topographic, energetic and developmental model of personality. Its theory has as many followers as it has opponents. However, his comprehensive and exceptionally deep clinical descriptions on the functioning of people with various mental disorders remain unrivalled. Contemporary psychoanalysis, especially the psychology of self and object relations theory, delivers exceptionally interesting and empirically verifiable concepts of mature and impaired personality (Kernberg, 1970, 1980; Mc Williams, 2009).

Humanistic psychology and cognitive psychology developed almost simultaneously to behaviourism. Observations made by Carl Rogers (1902-1987) during his clinical work with patients with mental disorders became the basis for a new concept of personality focused on the experience of Self. The notion became a subject of research which at first used clinical methods and then correlation procedures enabling an empirical verification of initial assumptions. At that time the precursor of the cognitive approach, George Kelly (1969), initiated a concept of personal constructs which were a result of perceiving oneself and other people in the social context. Inaccurate constructs of self and 
others cause too rigid or too chaotic functioning of a person, in contrast to accurate constructs which ensure flexible adjustment to reality. For Rogers the ideal person would be the one functioning fully, while for Kelly it would a sharp researcher and scientist.

Nowadays, more researchers continue and develop the cognitive approach than the humanistic one (Beck, 1976; Young \& Gluhoski, 1996). Traces of humanistic psychology can be seen among the authors of the integrative trend, e.g. Millon et al. (2005).

The beginnings of the statistical approach (called quantitative) should be linked with the students of Galton who formulated (still applicable) assumptions on the research method for inheritance, measurement and individual differences (Pervin, 2000). He was the one to introduce the notion of correlation coefficient; and his student, Karl Pearson (1857-1936), is the author of a statistical procedure known as the Pearson correlation (coefficient). Inspired by the work of Galton, Charles Spearman (1863-1945) not only tried to determine whether there was general intelligence, but also created a statistical method known as factor analysis intended for the detection of clusters (set) between coexisting variables. Factor analysis has been widely used in personality psychology and has become a source for the conceptualisation of further statistical methods distinguishing basic groups of traits or factors differentiating people.

Using the correlation method and factor analysis of a questionnaire Hans J. Eysenck $(1970,1990)$ described personality on three dimensions: introversion/extraversion, neuroticism (stability/instability) and psychoticism (sensitivity/insensitivity). At the beginning of the 1990s Costa and McCrea (1995) created the Five-Factor Model (FFM) indicating such traits as neuroticism, extraversion, conscientiousness, agreeableness and openness. It should be noted that FFM dimensions were used in the newest issue of DSM-V to describe individual types of personality disorders (First et al., 2012). Psychopathological classifications have never before used a selected personality concept in such a direct manner (even if only as a statistical model), indicating the necessary rule of theoretical neutrality.

Even this short presentation of the history of thought on personality disorders indicates that it was and is a subject of interest in many scientific fields. The development of knowledge on styles and disorders of personality is closely related to achievements of clinicians and theoreticians creating paradigmatic personality models, and with the progress within the methodology of clinical studies and statistics, especially with regard to tools for the creation of classification systems of mental disorders. Without doubt, the development can also be attributed to researchers creating international classifications of mental disorders and working as part of the World Health Organisation or the American Psychiatric Association.

\section{FROM DSM TO DSM-IV-TR}

After the Second World War it was necessary to work on a new version of the disorder classification, as many people, soldiers and civilians alike, suffered from more or less direct effects of the war. Clinicians called for the creation of a new classification system of mental disorders as the ones from the 1940s had allowed them only to diagnose one of the described psychoses (endogenic or psychogenic) or one of many described neuroses. In fact, they had been using a 1917 classification which diagnosed patients with more severe disorders in various areas of functioning as psychotic and those with less serious difficulties as neurotic. It transpired that war veterans suffered from a whole spectrum of clinical syndromes, of which as many as $90 \%$ did not match the clinical image of psychosis or neurosis (Coolidge \& Segal, 1998). Thus, most often they received a diagnosis of psychopathic personality which resulted in numerous negative consequences (APA, 1952). Such procedures were not only harmful, but also prevented people suffering from e.g. an acute or chronic post-traumatic stress disorder from receiving effective medical or psychotherapeutic help.

It is commonly assumed that the method of qualifying personality disorders in the post-war issue of DSM was greatly influenced by Kurt Schneider (1958), who defined it as a statistical deviation from the general standard adopted for a population (APA, 1952). His proposition was innovative in that, firstly, he stated that psychopathological personalities did not have to precede more severe mental disorders, but they might occur as an independent clinical entity. Secondly, he noticed that the development of personality disorders started in childhood and progressed through adolescence until adulthood. Thirdly, he described commonly observed psychopathological types of personality, most of which would be included in subsequent classification systems. Schneider distinguished the following types of psychopathic personality: depressive (depressive personality disorder), hyperthymic (manic personality), insecure (dependent personality), fanatical (paranoid personality disorder), explosive (impulsive personality in ICD), attention-seeking (histrionic personality disorder), labile (borderline personality disorder), affectless (antisocial personality disorder), weak-willed and asthenic (cf. Groth, 2010; Cierpiałkowska, 2013).

Referring to the classification of Schneider seven main categories of mental disorders, including 12 types of personality disorders, placed in three separate sections, four each, were distinguished in the first issue of DSM (1952). The first one included severe personality disorders (cardinal personality types) rarely, if at all, submitting to therapy, i.e. inadequate, schizoid, cyclothymic, paranoid personalities. The second included those personality disorders that 
formed not so much under the influence of the currently acting greater or lower stress, but resulted from disorders of emotional development and their clinical image included distinct symptoms of neurotic disorders, such as anxiety, conversions, phobias etc. This section included emotionally unstable personality, passive-aggressive personality, compulsive and other, not classified in other types of personality disorders. The third section included sociopathic personality impairments whose symptoms indicated either significant difficulties with submitting to sociocultural norms (antisocial and dissocial reactions) or sexual deviations or addictions (alcoholism and drug addiction). Later, the latter were diagnosed as ordinary symptoms of personality disorders and recognised as a personality disorder accompanying an addiction (DSM \& APA, 1952, p. 39).

The 1952 DSM used a categorical approach to personality disorders, atheoretical by definition, since it did not refer directly to a classification in a psychoanalytical, cognitive or integrative paradigm (Cierpiałkowska, 2004). Placing personality disorders in the classification of psychiatric disorders invested them with appropriate importance, which in subsequent years resulted in numerous research projects reviewing the categorization proposed in DSM-I. Most importantly, the accuracy of diagnostic procedures in recognising types of personality disorders based on reported symptoms was reviewed. The International Classification of Diseases used at the time in Europe did in fact include a section with mental disorders, but there were no personality disorders. It was only the eighth ICD that included them (WHO, 1968).

The first pre-war classification was reviewed at the end of the 1960s to develop DSM-II (APA, 1968) where ten main categories of mental disorders were distinguished. In Section V "Personality Disorders and Other Non-Psychotic Mental Disorders" ten specific types of personality disorders were placed and assigned code 301 . Sexual disorders, alcohol addiction and addiction to other psychoactive substances were marked 302 to 304 . It was found that personality disorders are characterised by deep, unadaptive patterns of behaviour different from psychotic and nervous disorders which develop in childhood and are recognised during adolescence or earlier (ibid., p. 41). The ten following personality disorders were distinguished: paranoid, cyclothymic, schizoid, impulsive, obsessive-compulsive, hysteric, asthenic, antisocial, passive-aggressive and inadequate. Two separate categories of personality disorders were also included, other and non-specific, but they were not described (Table 1). Although it was mentioned in DSM-I that personality disorders endure through life, only in DSM-II, as highlighted by Coolidge and Segal (1998), was it clearly emphasised that they begin in childhood. Despite numerous efforts to increase the accuracy of diagnosing personality disorders, it was continually unsatisfactory and required further work.

The 1980s brought further revisions of DSM with a completely new method of classifying mental disorders. The major change consisted in shifting from a uniaxial to a multiaxial diagnostic procedure which was expected to produce a more accurate and reliable clinical diagnosis. Clinically significant mental disorders such as schizophrenia, anxiety disorders, affective disorders and other were coded on Axis I, whereas personality disorders and disorders characteristic for childhood were placed on Axis II. Axis III was intended to estimate the health level, in particular physical and somatic issues, whereas Axis IV was for the assessment of psychosocial stress level in the patient's life (DSM-III \& APA, 1980). Placing personality disorders on a different axis than all the other mental disorders led to mental disorders of Axis I and Axis II being diagnosed by clinicians much more often.

The diagnosis of personality disorders in DSM-III was based on the occurrence of a certain number of personality traits characteristic for a specific disorder type (APA, 1980). Personality disorder was defined as persistent patterns of perception and thinking about the reality and self and entering into interpersonal relations, manifested in various areas of human life. These patterns are characterised by rigidity and unadaptiveness and cause deterioration in professional and social functioning leading to suffering. They occur already in adolescence or earlier, intensifying most notably in adulthood, and decreasing in strength later in life (ibid., p. 35). Eleven types of personality disorders were distinguished, namely: paranoid, schizoid, antisocial, borderline, compulsive, passive-aggressive, histrionic, schizotypal, narcissistic, avoidant and dependent. Only four personality disorders were included in all classifications, i.e. paranoid, schizoid, antisocial and passive-aggressive; two disorders were named according to DSM-I (not DSM-II), i.e. the notions of histrionic and compulsive personality disorders were reused; at the same time five new personality disorders were added, and four previous ones eliminated (Table 1). The category of atypical, mixed and other personality disorders was also added.

An important change in the classification of personality disorders in DSM-III was their grouping into three clusters. The cluster dominated by the characteristics of odd and eccentric included paranoid, schizoid and schizotypal personality disorders; the cluster dominated by the characteristics of being dramatic, emotional and erratic included narcissistic, histrionic, borderline and antisocial personality disorders; and the cluster with increased anxiety or fear included avoidant, dependent, passive-aggressive and compulsive personalities. 
After less than seven years, there was yet another revision of DSM where personality disorders were also coded on Axis II and combined into clusters similar to those specified in DSM-III, but marked A, B and $C$. Changes in the classification of personality disorders in DSM-III-R were minor as they applied to renaming one personality disorder and adding Annex A which included self-destructive and sadistic personalities (APA, 1987). Obsessive disorder received the name used in DSM-I, obsessive-compulsive personality disorder.

The prevalence of personality disorders in the 1990 s was estimated at $10-13 \%$ of the population. At the same time it was observed that many people fulfilled the criteria of more than one personality disorder (Clonninger, 1997). Apart from the accompanying symptoms of various personality disorders, disorders from Axis I and Axis II were also observed, and it was estimated that in some cases, e.g. in an addiction to psychoactive substances or alcohol, a personality disorder occurred in approximately $50 \%$ of patients (Skodol, Oldham \& Gallaher, 1999).

Personality disorders in DSM-IV, another revision of the previous propositions, were defined as an enduring pattern of inner experience and behaviour that deviates markedly from the expectations of the individual's culture (APA, 1994). The diagnosis of this clinical entity was performed on the basis of the following diagnostic criteria:

A. The pattern should manifest in at least two (out of four) of the following areas:

1) cognitive, i.e. in methods of perceiving and interpreting oneself, other people and events;

2) affective, i.e. in the strength, degree of changeability and adequacy of emotional reactions;

3) interpersonal functioning;

4) control of impulses.

B. This pattern is inflexible and pervasive across a broad range of personal and social situations and leads to clinically significant distress or impairment in social, occupational, or other important areas of functioning.

C. The pattern is stable and of long duration, and its onset can be traced back at least to adolescence or early adulthood.

D. The pattern is not accounted for as a manifestation or consequence of another mental disorder.

E. This pattern is not due to the direct physiological effects of a substance (e.g., drugs or medications) or a general medical condition (e.g. head trauma) (APA, 1994).

In DSM-IV and the next revision DSM-IV-TR the division of personality disorders into three clusters was kept (APA, 1994, 2000):

- cluster A - personality disorders characterised by odd and eccentric behaviour; paranoid, schizotypal and schizoid personalities;
- cluster B - disorders characterised by dramatic, emotional behaviour and disregard for consequences; narcissistic, borderline, histrionic and antisocial personalities;

- cluster C - personality disorders characterised by anxiety, fear and terror; avoidant, dependent and obsessive-compulsive personality.

A separate class was NOS (Not Otherwise Specified). The category was created for those personality types that did not fulfil the criteria of clusters A, B or C. An example of this may be the occurrence of characteristics typical for more than one personality disorder, that is, a mixed personality whose symptoms cause significant suffering or deterioration in one area of functioning (e.g. social or professional). If a clinician diagnoses a personality disorder not included in Axis II, he or she should classify it in this category. Such a procedure applies for instance to depressive or passive-aggressive (also called negativistic) personalities included in Annex B (more: Cierpiałkowska, 2004, 2009).

Despite numerous changes in the classification of mental disorders (including personality disorders), DSM-IV (APA, 1996) and DSM-IV-TR (APA, 2000) were dominated by the categorical approach. However, doubts as to the adequacy of this presentation of disorders were continuously arising, as there was no increase in the accuracy of nosological diagnosing with regard to personality disorders (cf. Hopwood et al., 2012).

\section{HYBRID MODEL OF PERSONALITY DISORDERS - DSM-V}

Empirical verifications confirmed high theoretical accuracy of schizotypal, borderline and antisocial personality disorders, whereas the accuracy of other types from clusters A, B and C was much lower (Bell \& Jackson, 1992; Sanislow et al., 2002). Schizotypal personality often precedes schizophrenia, which is not observed for schizoid personality. There is also no evidence for the theoretical accuracy of isolating histrionic and narcissistic personalities from cluster $\mathrm{B}$ and avoidant personality from cluster $\mathrm{C}$, which seems to be a certain fixed form of social fear. Clinicians highlight that narcissistic and histrionic symptoms are observed in patients with various mental disorders, as well as within the broad sense of normal (Oldham, 2010). The following personality disorders were distinguished in DSM-V (2013): schizotypal, borderline, antisocial, avoidant and obsessive-compulsive; others will be considered unspecific or qualified as other disorders.

In DSM-V (2013) normal and impaired personalities are described in three aspects: impaired integration of identity and feeling of self; impairments in interpersonal functioning related to poor recogni- 
Table 1

Personality disorders in DSM classifications (Cierpiatkowska, 2013)

\begin{tabular}{|c|c|c|c|c|c|}
\hline DSM-I (1952) & DSM-II (1968) & DSM-III (1980) & $\begin{array}{c}\text { DSM-III-TR } \\
(1987)\end{array}$ & $\begin{array}{c}\text { DSM-IV (1994) } \\
\text { i DSM-IV-TR } \\
(2000)\end{array}$ & DSM-V \\
\hline paranoid & paranoid & paranoid & paranoid & paranoid & - \\
\hline schizoid & schizoid & schizoid & schizoid & schizoid & - \\
\hline antisocial & antisocial & antisocial & antisocial & antisocial & antisocial \\
\hline borderline & - & borderline & borderline & borderline & borderline \\
\hline compulsive & $\begin{array}{l}\text { obsessive- } \\
\text { compulsive }\end{array}$ & compulsive & $\begin{array}{l}\text { obsessive- } \\
\text { compulsive }\end{array}$ & $\begin{array}{l}\text { obsessive- } \\
\text { compulsive }\end{array}$ & $\begin{array}{l}\text { obsessive- } \\
\text { compulsive }\end{array}$ \\
\hline $\begin{array}{l}\text { passive- } \\
\text { aggressive }\end{array}$ & $\begin{array}{l}\text { passive- } \\
\text { aggressive }\end{array}$ & $\begin{array}{l}\text { passive- } \\
\text { aggressive }\end{array}$ & $\begin{array}{l}\text { passive- } \\
\text { aggressive }\end{array}$ & - & - \\
\hline cyclothymic & cyclothymic & - & - & - & - \\
\hline inadequate & inadequate & - & - & - & - \\
\hline dyssocial & - & - & - & - & - \\
\hline $\begin{array}{c}\text { sexual deviation } \\
\text { specify }\end{array}$ & - & - & - & - & - \\
\hline \multirow[t]{13}{*}{ addiction } & - & - & - & - & - \\
\hline & impulsive & - & - & - & - \\
\hline & histrionic & histrionic & histrionic & histrionic & - \\
\hline & asthenic & - & - & - & - \\
\hline & & schizotypal & schizotypal & schizotypal & schizotypal \\
\hline & & narcissistic & narcissistic & narcissistic & narcissistic \\
\hline & & avoidant & avoidant & avoidant & avoidant \\
\hline & & dependent & dependent & dependent & - \\
\hline & & & Appendix A & Appendix B & $\begin{array}{l}\text { Personality } \\
\text { Disorder-Trait } \\
\text { Specified } \\
\text { (PD-TS) }\end{array}$ \\
\hline & & & self defeating & - & \\
\hline & & & sadistic & - & \\
\hline & & & - & $\begin{array}{l}\text { passive- } \\
\text { aggressive }\end{array}$ & \\
\hline & & & - & depressive & \\
\hline
\end{tabular}

tion of motivations in the behaviour of other people, weaker empathy; and pathological personality traits characteristic for each type of personality disorder. In previous DSM issues greater attention was paid to such symptoms as emotional dysregulation, difficulties in controlling drives, or cognitive impairments. There were also numerous doubts concerning the categorical approach to personality disorders and 
tendency to treat them in a dimensional manner. Thus, it is proposed to assess the manifestations of impaired functioning on a 4-point scale: no impairment ( 0 points), mild impairment (1 point), moderate impairment ( 2 points), severe impairment (3 points) and extreme impairment (4 points). Such an assessment system would allow us to use the dimensional approach and diagnose the personality style (Firs et al., 2002; Oldham, 2010).

In consequence, DSM-V adopted a hybrid, categorical-dimensional model of personality disorders, assuming that their basic characteristics are impairments of personality functioning (self and interpersonal functioning) and presence of pathological personality traits. For a personality disorder to be diagnosed the following criteria must be met:

Significant impairment in intrapsychic area a) or b):

Identity defined as understanding self, with clear borderlines between self and others; stable self-evaluation and self-esteem, ability to experience and regulate various emotions,

b) self-direction, described as striving to achieve coherent and important short-term goals, use constructive, prosocial standards of behaviour, ability for productive self-reflection;

- and in the interpersonal area a) or b):

a) empathy defined as understanding and appreciating experience and motivation of others, tolerance for different perspectives and understanding one's impact on the behaviour of others,

b) intimacy, understood as the depth and stability of relationships with others, desire and ability to be close, manifestation of mutual respect in interpersonal relations.

B. One or more pathological traits or aspects in manifestation of traits from five areas, characterised by 25 clusters.

C. Impairment in the functioning of personality and expression of the individual's traits are relatively stable across time and persistent across situations.

D. Impairment in personality functioning and the individual's trait expression are not normative for the individual's developmental stage or sociocultural environment.

E. Impairment in personality functioning and the individual's personality trait expression are not solely due to the direct effects of a substance (e.g. drug, medication) or a general medical condition (e.g. severe head trauma).

Specific personality disorders not changed in DSM-V are schizotypal, antisocial, borderline, narcissistic, obsessive-compulsive and avoidant personality disorders. Other disorders are classified as other, non-specific personality disorders. This proposed classification has already given rise to heated discussions and disputes whose participants wait for the results of studies confirming or challenging their reservations. Based on a thorough review of the history of diagnosing person- ality disorders, it may be concluded that there is a new era of studies on this type of mental disorders and that the results of these studies will certainly encourage theoreticians and researchers to further consider and introduce changes in the classification proposed in DSM-V (cf. Hopwood et al., 2012; Livesley, 2012).

Despite numerous studies and the resulting introduction of the dimensional-categorical model of personality disorders, three basic issues presented by numerous researchers for many years have been resolved only partially (Lenzenweger \& Clarkin, 1996). First of all, to what extent should the procedure of isolating mental disorders include concepts of prototypes, multidimensional dimensions or categories of normal or impaired personality types? Secondly, is there certain continuity among traits of normal and pathological personalities or are they two separate categories? Thirdly, what is the character of basic processes and properties of normal and impaired personality structure?

\section{REFERENCES}

American Psychiatric Association (1952). Diagnostic and Statistical Manual: Mental Disorders. Washington DC: American Psychiatric Association.

American Psychiatric Association (1968). Diagnostic and Statistical Manual of Mental Disorders, $2^{\text {nd }}$ ed. Washington DC: American Psychiatric Association.

American Psychiatric Association (1980). Diagnostic and Statistical Manual of Mental Disorders, $3^{\text {rd }}$ ed. Washington DC: American Psychiatric Association.

American Psychiatric Association (1987). Diagnostic and Statistical Manual of Mental Disorders, $3^{\text {rd }}$ ed. Revised. Washington DC: American Psychiatric Association.

American Psychiatric Association (1994). Diagnostic and Statistical Manual of Mental Disorders, $4^{\text {th }}$ ed. Washington DC: American Psychiatric Association.

American Psychiatric Association (2000). Diagnostic and Statistical Manual of Mental Disorders, $4^{\text {th }}$ ed. Text Revision. Washington DC: American Psychiatric Association.

American Psychiatric Association (2013). Diagnostic and Statistical Manual of Mental Disorders, $5^{\text {th }}$ ed. Washington DC: American Psychiatric Association.

Arrigo, A.B. \& Shipley, S. (2001). The confusion over psychopathy (I): Historical considerations. International of Offender Therapy and Comparative Criminology, 45, 325-344.

Beck, A.T. (1976). Cognitive therapy and the emotional disorders. Oxford: International Universities Press.

Beck, A.A., Freeman, A. \& Davison, D.D. (2005). Cognitive Therapy of Personality Disorders. Kraków: Wydawnictwo Naukowe UJ.

Bell, R.C. \& Jackson, H.J. (1992). The structure of personality disorders in DSM-III. Acta Psychiatrica Scandinavica, 85, 279-287. 
Cierpiałkowska, L. (2004). Zaburzenia osobowości w modelach medycznych i psychologicznych. In: L. Cierpiałkowska (ed.). Psychologia zaburzeń osobowości. Wybrane zagadnienia [Psychology of personality disorders. Selected issues]. Poznań: Wydawnictwo Naukowe UAM.

Cierpiałkowska, L. (2009). Psychopatologia [Psychopathology]. Warszawa: Wydawnictwo Naukowe Scholar.

Cierpiałkowska, L. (2013). From categorical to a hybrid model of personality disorders - the history and the present classification system DSM. In: T. Rzepa \& C.W. Domański (eds.). Na drogach i bezdrożach historii psychologii [The history of psychology - on and off-road] (Volume 3, pp. 44-64). Lublin: Wydawnictwo UMCS.

Clarkin, J.F. (2006). Conceptualization and treatment of personality disorders. Psychotherapy Research, 16, 1-11.

Clonninger, C.R. (1997). A psychobiological model of personality and psychopathology. Journal of Psychosomatic Medicine, 37, 91-102.

Coolidge, F.L. \& Segal, D.L. (1998). Evolution of personality disorders diagnosis in the Diagnostic and Statistical Manual of Mental Disorders. Clinical Psychological Review, 18, 585-599.

Costy, R.R. \& McCrea, P.T. Jr. (1995). Trait explanations in personality psychology. European Journal of Personality, 9, 231-252.

Eysenck, H.J. (1970). The structure of human personality, $3^{\text {rd }}$ ed. London: Methuen.

Eysenck, H.J. (1990). Biological dimensions of personality. In: L.A. Pervin (ed.). Handbook of personality: Theory and research (pp. 244-276). New York: Guilford Press.

First, M.B., Bell, C.C. \& Cuthbert, B. (2002). Personality Disorders and Relational Disorders: A Research Agenda for Addressing Crucial Gaps in DSM. In: D.J. Kupfer, M.B. First \& D.A. Regier (eds.). $A R e-$ search Agenda for DSM-V (pp. 123-200). Washington, DC: American Psychiatric Association.

Groth, J. (2010). Oblicza psychopatii [Faces of psychopathy]. Warszawa: Wydawnictwo Naukowe Scholar.

First, M.B., Bell, C.C., Cuthbert, B. Krytal, J.H. \& Malison, R. (2012). Personality disorders and relational disorders: A research agenda for addressing crucial gaps in DSM. In: D.J. Kupfer, M.B. First \& D.A. Regier (eds.). A research agenda foe DSM-V (pp. 123200). Washington DC: American Psychiatric Association.

Hopwood, Ch.J., Thomas, K.M., Markon, K.F., Wright, A.G.C. \& Kruegere, R.F. (2012). DSM-5 personality traits and DSM-IV personality disorders. Journal of Abnormal Psychology, 121, 424-432.

Jung, C.G. (1921/1971). Psychological types. In: The collected works of C.G. Jung (Volume 6). Princeton, NJ: Princeton University Press.
Kelly, G.A. (1969). The psychology of personal constructs. A theory of personality (Volume 1). New York: W.W., Norton and Co.

Kernberg, O.F. (1970). A psychoanalytic classification of character psychopathology. Journal of the American Psychoanalytic Association, 18, 800-822.

Kernberg, O.F. (1980). Psychotherapy with borderline patients: An overview. In: B. Karasu \& L. Bellak (eds.). Specialized techniques for specific clinical problems in psychotherapy (pp. 85-117). Northvale, New Jersey, London: Jason Aronson Inc.

Lenzenweger, M.F. \& Clarkin, J.F. (1996). The personality disorders: History, classification, and research issues. In: M.F. Lenzenweger \& J.F. Clarkin (eds.). Major theories of personality disorders (pp. 1-42). New York, London: The Guilford Press.

Livesley, J. (2012). Current issues in the classification of personality disorder. botp.datasenter.no/ wp-content/uploads

Mc Williams, N. (2009). Diagnoza psychologiczna [Psychoanalytic Diagnosis]. Gdańsk: Gdańskie Wydawnictwo Psychologiczne.

McCord, W. \& McCord, J. (1964). The psychopath: An essay on the criminal mind. New York: Van Nostrand Reinhold Company.

Millon, T., Davis, R., Millon, C., Escovar, L. \& Meagher, S. (2005). Zaburzenia osobowości we wspótczesnym świecie [Personality disorders in modern life]. Warszawa: Instytut Psychologii Zdrowia.

Mischel, W. (1990). Personality dispositions revisited and revised: A view after three decades. In: L.A. Pervin (ed.). Handbook of personality. Theory and research (pp. 111-134). New York: Guilford Press.

Oldham, J.M. (2010). Psychodynamic treatment planning and the official diagnostic system: toward DSM-V. In: J.F. Clarkin, P. Fonagy \& G.O. Gabbard (eds.). Psychodynamic psychotherapy for personality disorders: A clinical handbook (pp. 412456). Washington DC: American Psychiatric Association.

Oleś, P.K. \& Drat-Ruszczak, K. (2010). Osobowość. In: J. Strelau \& D. Doliński (eds.). Psychologia. Podręcznik akademicki [Psychology. Handbook of Psychology] (pp. 651-763). Gdańsk: Gdańskie Wydawnictwo Psychologiczne.

Pervin, L.A. (2000). Psychologia osobowości [Psychology of personality]. Gdańsk: Gdańskie Wydawnictwo Psychologiczne.

Sanislow, C.A., Morey, L.C., Grilo, C.M., Gunderson, J.G., Shea, M.T., Skodol, A.E., Stout, R.L., Zanarini, M.C. \& McGlashan, T.H. (2002). Confirmatory factor analysis of DSM-IV borderline, schizotypal, avoidant and obsessive-compulsive personality disorders: findings from the Collaborative Longitudinal Personality Disorders Study. Acta Psychiatrica Scandinavica, 105, 28-36.

$\mathrm{Sa} \beta$, H. \& Felthous, A.R. (2007). History and conceptual development of psychopathic disorders. In: 
A.R. Felthous \& H. Saß (eds.). The international handbook of psychopathic disorders and the law (pp. 9-30). New York: Wiley \& Sons, Ltd.

Schneider, K. (1958). Psychopathic personalities. London: Cassell.

Skodol, A.E, Oldham, J.M. \& Gallaher, P.E. (1999). Axis II comorbidity of substance use disorders among patients referred for treatment of personality disorders. American Journal of Psychiatry, 156, 733-738.

Strelau, J. (1985). Temperament, osobowość, działanie [Temperament, personality, action]. Warszawa: PWN. Strelau, J. (2000). Osobowość i różnice indywidualne. In: J. Strelau (ed.). Psychologia. Podręcznik akademicki [Psychology. Handbook of Psychology] (Volume 2; pp. 523-560). Gdańsk: Gdańskie Wydawnictwo Psychologiczne.

Widiger, T.A. \& Costa, P.T. (1994). Personality and personality disorders. Journal of Abnormal Psychology, 103, 78-91.

World Health Organization (1968). The ICD-8 Classification of Mental and Behavioural Disorders. Diagnostic criteria for research. Geneva: World Health Organization.

www.dsm5org. Personality disorders

Young, J.E. \& Gluhoski, V.L. (1996). Schema-focused diagnosis for personality disorders. In: F.W. Kaslow (ed.). Handbook of relational diagnosis and dysfunctional family patterns (pp. 300-321). New York: John Wiley \& Sons. 